Second impression. Crown 8vo. pp. xxii +328 . Price 5s. net.

\title{
SCIENCE AND THE NATION
}

\author{
ESSAYS BY CAMBRIDGE GRADUATES
}

WITH AN INTRODUCTION BY THE

RIGHT HON. LORD MOULTON, K.C.B., F.R.S.

\author{
EDITED BY \\ A. C. SEWARD, F.R.S. \\ MASTER OF DOWNING COLLEGE, CAMBRIDGE
}

It is the aim of the authors of these essays to present the results of experience in scientific investigation, to illustrate by concrete examples the sources of progress in a few departments of knowledge and so make clear to the layman the position of research as a factor in national prosperity. Each Essay has been written by some one who, by lifelong study and practice of the Branch of Science to which it relates, has qualified himself to give a just and authoritative description of the work that has already been done as well as of the bearing of that work on the present and its promise for the future.

\section{Extracts from Press Notices}

"One of the most important and most illuminating of recently published volumes on the place of science in national life... The admirable essays contained in the volume give assurance that the men who are chiefly responsible for the direction of scientific instruction in this country have the root of the matter in them, that British science is sound and vigorous at its centre, and that what is mainly required is the intellectual and financial support of the nation as a whole,"

Leading Anicle in T be Glasgoro Herald

"This is a fascinating book, and it fulfils its purpose admirably of helping ordinary people to grasp the value of scientific research... The essays are the clearest popular exposition with which we are acquainted of the achievements of modern science in the service of man."-Tbe Inquirer

"In essay after essay-from the impressive opening one on 'The National Importance of Chemistry' to that on 'The Government of Subject Peoples,' which concludes the series- -we have a recital of the achievements of science in its various branches, and it is brought home to us in the most convincing manner how the great discoveries and inventions-coal-tar dyes, $\mathrm{X}$-rays, wireless telegraphy, the production of a rust-resisting wheat of large yielding capacity, the modern treatment of disease - have all been rendered possible and are all the outcome of a 'steady pursuit of knowledge by rational and intelligent research.'"-Tbe Neto Statesman

"The chapters are of the utmost interest to the general reader; they give him compactly and authoritatively a sound idea of the scope and value of contemporary work in chemistry, physica, botany, geology, medicine, mathematics, and anthropology." -N ature

"The whole region of scientific research is surveyed by the contributors to Science and tbe Nation, and their observations will be invaluable to those who really wish to have a firm grasp of the true problems of intellectual reconstruction on the scientific side." - Tbe Morning Post

Cambridge University Press, Fetter Lane, London, E.C. 4 C. F. Clay, Manager 


\section{CONTENTS}

(All rights reserved)

Cutler, D. WARD. Observations on Entamoeba histolytica.

(With Plate VII and I Text-figure) . . . .

Dobelu, Chifford, A Revision of the Coccidia Parasitic in Man. (With Plate VIII and 2 Text-figures) . . .

Bassett-Smith, P. W. A Short Laboratory Study of Spirochaeta icterohaemorrhagiae. (With Plate IX and 1 Chart) . .

Nuttall, Georen H. F. The Biology of Pediculus humanus. (With Plate $\mathrm{X}$ and 1 Text-figure) . . . .

BAcot, A. and TALвот, G. The Comparative Effectiveness of Certain Culicifuges under Laboratory Conditions. (With 1 Text-figure) . . . . . . . .

Kenrs, D. Supplementary Note on the Formation of a Cocoon by Cyclorhaphous Dipterous Larvae .

$P A R A S I T O L O G Y$ is published about four times a year. The numbers afterwards are issued in volumes each containing four numbers and amounting to about 500 pages, with plates and figures.

Papers for publication should be sent to Professor Geo. H. F. Nutrati, F.R.S., Longfield, Madingley Road, Cambridge. Other eommunications should be addressed to the University Press, Cambridge.

Papers forwarded to the Editors for publication are understood to be offered to PARASITOLOGY alone, unless the contrary is stated.

Contributors receive fifty copies of their papers free. Additional copies, not exceeding one hundred (except in special cases), may be had at cost price: these should be ordered when the final proof is returned.

The subseription price is $21.15 s$, per volume (post-free), payable in advance; single numbers $128,6 d$. net (double number $25 s$, net). Subscribers to the Journal of Hygiene may obtain single numbers of PARASITOLOGY at the reduced price of 108 . net, or may become subscribers at the reduced rate of $£ 1$. 5s. per volume. Subscriptions may be sent to any Bookseller, or to Mr C. F. Clay, Manager, Cambridge University Press, Fetter Lane, London, E.C. 4.

The Cambridge University Press has appointed the University of Chicago Press agents for the sale of Parasitology in the United States of America and has authorised them to charge the following prices: Subscription $\$ 8.75$ net per volume; single numbers $\$ 3.25$ net each, double numbers $\$ 6.25$ net each. Subscribers to the Journal of Hygiene may obtain single numbers of Parasitology at the reduced price of $\$ 2.50$ net, or may become subseribers at the reduced rate of $\$ 6.25$ per volume.

The prices of back volumes are as follows :

Volumes I, II, III and IV (1908-11). Each volume in four parts, paper covers, 258 , net per volume. Bound in buckram, 30s, net per volume.

Volumes V, VI, VII, VIII, IX and X (1912-18). Each volume in four parts, paper covers, 35 s. net per volume. Bound in buckram, 40 s, net per volume,

Cases for binding volumes can be supplied at $38,6 d$. net each. 